\title{
ISMAEL E ISAQUE IRMANADOS: OS JUDEUS NOS ROMANCES DE MILTON HATOUM
}

\section{ISMAEL AND ISAAC BROTHERS: THE JEWS IN THE NOVELS OF MILTON HATOUM}

\begin{abstract}
Alessandra F. Conde da Silva*
Resumo: Judeus e árabes na Amazônia vivem pacificamente? Em três romances de Milton Hatoum, Relato de um certo Oriente (1989), Dois irmãos (2000), Órfãos do Eldorado (2008), personagens judeus e árabes convivem harmoniosamente, sem dar sinais de conflitos e querelas, cuja incidência remonta aos tempos bíblicos. Nesse sentido, metaforicamente, Ismael e Isaque vivem bem, festejando a sua estrangeiridade na acolhedora e quente Manaus. Ainda que não sejam protagonistas nos romances, a presença dos judeus marroquinos é contígua à história imigratória dos personagens sírio-libaneses, desbravadores, assim como os judeus, dos rios e da floresta amazônica. Este artigo estuda a presença judaica e árabe na obra de Milton Hatoum a partir das reflexões de Samuel Benchimol, Regina Igel, Márcio Souza.
\end{abstract}

Palavras-chave: Romances de Milton Hatoum. Judeus marroquinos. Amazônia.

Abstract: Jews and Arabs in the Amazon living peacefully? In three novels by Milton Hatoum, Relato de um certo Oriente (1989), Dois Irmãos (2000), Órfãos do Eldorado (2008), Jewish and Arab characters coexist harmoniously, without showing signs of conflicts and quarrels, whose incidence goes back to biblical times. In this sense, metaphorically, Ismael and Isaque live well, celebrating their foreignness in the welcoming and warm Manaus. Although they are not protagonists in the novels, the presence of Moroccan Jews is contiguous with the immigration story of the Syrian-Lebanese characters, pathfinders, as well as the Jews, from rivers and the Amazon rainforest. This article studies the Jewish and Arab presence in Milton Hatoum's work based on the reflections of Samuel Benchimol, Regina Igel, Márcio Souza.

Keywords: Novels by Milton Hatoum. Moroccan Jews. Amazon.

\footnotetext{
* Universidade Federal do Pará, Bragança, Brasil, Doutorado em Letras e Linguística pela Universidade Federal de Goiás, professor de literatura portuguesa.

E-mail: <afcs77@ hotmail.com>.
} 


\section{1- Ismael e Isaque irmanados}

De Abraão e da escrava Agar nasceu Ismael, o primogênito. De Sara, a esposa, e de Abraão, procedeu Isaque, conforme se sabe da narrativa bíblica. A tradição cristã, concebeu, com Santo Agostinho (1995, p. 156), "que en los dos hijos de Abrahán, el uno de la esclava y el otro de la libre, se entienden los dos Testamentos". Para além da compreensão simbólica de que os meninos de Abraão simbolizariam o Antigo e o Novo Testamento, alhures se entende ainda que Ismael é o ancestral dos árabes, como Isaque o é dos judeus, concepção que a Idade Média cultivou, como se vê em Semeiança del mundo, de autoria anônima. Deste livro, diz José Rivair Macêdo (2001, p. 21), há dois manuscritos, um do século XIII e outro do século XV. Apresenta-se nele a indicação de que os árabes são descendentes da escrava Agar, mãe de Ismael. A Legenda Áurea de Jacopo de Varazze (2003, p. 1007) perpetuou a tradição de correlacionar árabes e Ismael, quando, ao apresentar a história de São Pelágio, toca no assunto sobre Maomé "que seduziu os agarenos ou ismaelitas”. A mesma tradição tem nos judeus a progênie de Isaque, por uma ordem genealógica, e também de cristãos, no âmbito espiritual. Santo Agostinho (1995, p. 754) o denomina "nuestro padre".

A Bíblia diz que Ismael foi enviado juntamente com a sua mãe Agar para longe da convivência familiar. Expulsos e desamparados, no deserto foram visitados por um anjo que garantiu à mãe, em desespero, a salvaguarda de seu filho sedento e quase moribundo, como se pode ler em Gênesis 21: 17-181: “"Que tens, Agar? Não temas, pois Deus ouviu os gritos da criança, do lugar onde ele está. Ergue-te! Levanta a criança, segura-a firmemente, porque eu farei dela uma grande nação". Na tradição judaica, mais propriamente no Midrash, conta-se que Ismael certa vez atirou flechas contra o menino Isaque, o que provocou o medo e a ira de sua mãe Sara (WEISSMAN, 2006, p. 161). O Midrash é um gênero da "literatura rabínica que consiste na exegese e interpretação, tanto da Halachá [normas e regulamentos da Torá], como da Hagadá [narrativas fabulares ou lendas criadas por sábios e rabinos]" (BEREZIN, 1997, p. 187). Há nos midrashim (em hebraico, plural de Midrash) alargamentos narrativos à matéria bíblica, como se vê, por exemplo, na conversa entre Hashem (designação atribuída a Deus que significa, em hebraico, O Nome) e os anjos a respeito do porquê auxiliar Ismael em seu padecimento, se os filhos de Ismael negariam água a Israel, no futuro, dando a entender que seriam

\footnotetext{
${ }^{1}$ Todas as referências bíblicas neste trabalho foram retiradas da Bíblia de Jerusalém.
} 
nações inimigas. Ao que Hashem explicou: "Yo juzgo a un hombre según sus actos presentes. Ishmael mismo no es culpable de matar a alguien de sed. No lo castigaré ahora por los errores que sus descendientes cometrán en el futuro" (WEISSMAN, 2006, p. 163).

Além disso, o Midrash dá a Ismael um caráter bélico e selvagem. Acusa-o de vagamundo e errante. Cita o prognóstico dos anjos, em um relato a Agar, que o menino habitaria no deserto e seria hábil caçador, atribuindo-lhe como descendente o poderoso Nevujadnetzar (Nabucodonosor, rei de Babilônia, na época de Daniel) e que faria guerra a todos e todos o atacariam (WEISSMAN, 2006, p. 133). Segundo o professor Mahdi Abdul Hadi (2019, p. 14-15), considerando uma perspectiva árabe,

in around the 18th century BC, Abraham came from Ur in south Mesopotamia (Iraq) to the Land of Canaan. He settled somewhere in the Jordan Valley. As the old and new testaments had not been revealed when he was alive, Abraham religion was neither a Jewish nor a Christian, but a believer in the oneness of God. He was reported in Genesis as worshipping "the most high God." The Holy Qur'an mentions that he was a "Muslim," not in the modern definition of one who follows the laws revealed in the Qur'an, but rather in the sense of having given his "submission to the will of God." Thus Christians, Muslims and Jews still pray for him in all their prayers, as they believe God has enjoined them to do. Abraham's concubine Egyptian Hagar bore his son Ishmael, to whom present-day Arabs now trace their descent; meanwhile his first wife Sarah bore his son Isaac, to whom present-day Jews claim their lineage. Abraham moved to a place near Hebron (al-Khalil), where he lived preaching monotheism. When he died, his two sons, Ishmael and Isaac buried him in the same cave in which his wife Sarah was buried.

A rivalidade entre árabes e judeus ganhou maior expressividade nas últimas décadas com o acirramento do conflito árabe-israelense, no Oriente Médio, ainda que a História testemunhe a recorrência dos confrontos e hostilidades seculares.

$\mathrm{Na}$ Amazônia, árabes e judeus conviveram pacífica e respeitosamente, embora a violência e a perseguição dos árabes contra os judeus tenha sido uma das causas da emigração judaico-marroquina para a Amazônia, como veremos (BENCHIMOL, 2008, p. 44). Isaac Laredo em Memórias de un viejo tangerino narra que

em 1735, em Tânger, um notável hebreu, Abraham Serruya, fez uma petição ao sultão e foi atendido, para obter um novo cemitério mais perto, porque no cemitério existente perto de Grand Boulevard os moleques muçulmanos atiravam pedras nos cortejos fúnebres, 
impulsionados pelo fanatismo e pela ignorância, sem que isso pudesse ser evitado pelas autoridades (LAREDO, 1935, p. 396).

A literatura na Amazônia, ao contrário, dá indícios de uma relação amistosa. $\mathrm{Na}$ crônica "Num tempo de diferenças amenas ou a paz esteja convosco" de $O$ fim do mundo e outras histórias de beira-rio, de Elias Salgado, ficamos sabendo da amizade do pai do narrador, um judeu de origem judaico-marroquina, e de um libanês. O narrador diz: “[...] no passado, em Boca do Acre, na minha Manaus e na nossa comunidade, a convivência com os árabes era muito boa e nada tinha do ranço político e da violência que possui o Oriente Médio" (SALGADO, 2015, p. 74). A família de Youssef Afif era muito amiga dos Elmaleh-Salgado. A esposa de Yossef, D. Lili, uma árabe cristã, era chamada de Lilit (suposta primeira esposa de Adão que virou um demônio segundo os mitos judaicos) quando enervava o compadre David Salgado. Era mais um "jogo de representação" (SALGADO, 2015, p. 77). O judeu Salgado era, na verdade, grande amigo do árabe muçulmano Afif. Com a perda do amigo, Afif homenageou-o com um texto que revela o respeito e a amizade de dois descendentes de Abraão. No texto de autoria de Yossef Afif é dito que David Salgado

jamais fez restrições a um sobrenome árabe. As adversidades históricas seculares estimulavam-lhe o gosto de viver e de compartilhar alegria, estendendo a mão para todos.

Familiares seus permaneceram lá, velando o nome honrado de um paradigma de convivência pacífica, do trabalho inteligente, da grandeza moral de um povo que, através dos séculos sobreviveu a desditas e discriminações.

...Leves a minha lembrança, o meu apreço, para te falarem. Nossas mãos apertam num abraço, os nossos corações, amigo DAVID ... de ISRAEL.

Unamo-nos... Nos amemos...

$\mathrm{Na}$ metamorfose dos teus outrora desertos, colheríamos flores nos jardins...

Cortaríamos os nossos pulsos, misturaríamos nossos sangues aparentados e, num pacto bendito, selaríamos a paz para a eternidade, substituindo as disputas já centenárias, por uma convivência cordial e fraterna.

Iríamos a Meca e Medina. Farias comigo a curvatura muçulmana, evocaríamos Alá. Em Tel Aviv e Jerusalém, nas sinagogas, oraríamos pelos teus ancestrais.

Deixaríamos de ser os primos execrados. (SALGADO, 2015, p. 78-79). 
Milton Hatoum tem romances em que judeus e "árabes” (qualificativo genérico para muçulmanos) aparecem sem o epíteto de "primos execrados" (SALGADO, 2015, p. 79). Como veremos adiante, Ismael e Isaque vivem irmanados, num sentido metafórico, e festejando a sua estrangeiridade na cálida Manaus.

\section{2- Os judeus nos romances de Milton Hatoum}

Franceses, italianos, alemães, japoneses e libaneses não foram os únicos grupos étnicos retratados nas obras de Milton Hatoum. A lista é generosa. Manaus tornou-se o berço que acolhe várias culturas e vários povos. Um grupo em particular, os judeus marroquinos, aparece nos romances Relato de um certo Oriente (1989), Dois irmãos (2000) e Órfãos do Eldorado (2008). Além dos libaneses, grupo étnico dos protagonistas de Relato de um certo Oriente e Dois irmãos, Milton Hatoum apresenta personagens estrangeiros ou cita outros povos imigrantes na Amazônia.

Em Relato de um certo Oriente, Emilie e seu marido são os geradores de uma família de imigrantes sírio-libaneses. Ela, uma cristã maronita e ele, um muçulmano. A história começa a ser contada numa Manaus da Belle Époque, durante o primeiro Ciclo da borracha, nas primeiras décadas do século XX, quando os imigrantes árabes aportaram na região. O dia-a-dia desta família peculiar e a lida no comércio mostram os aspectos peculiares de sua cultura, capitalizada pela presença de outros estrangeiros e de um jeito próprio de viver na Amazônia.

O cosmopolitismo da Manaus de Hatoum pode ser percebido não apenas pela afluência do personagem estrangeiro, mas até mesmo pelos itens importados vendidos no comércio dos protagonistas árabes, ou na alimentação da família. Pratos e sabores dos levantinos estão em suas mesas amazônicas. Manaus acolhe bem os seus turistas e imigrantes. Estes, todavia, honram as suas tradições, procurando na alimentação e no comércio manter a sua cultura, como pode ser visto, principalmente, em Relato de um certo Oriente. A forma como um animal é abatido, por exemplo, revela não apenas ecos ou rituais religiosos, mas a reificação da tradição. As querelas sobre uma ave entre a matriarca cristã e o patriarca islâmico da família libanesa de Relato de um certo Oriente, mostram mais que rusgas religiosas. Como deveria o animal ser morto? Para o libanês, o 
sangue deveria ser vertido sobre a terra, como a tradição islâmica ensina. Para a cristã, outros artifícios poderiam ser utilizados no processo, como o uso de bebida alcoólica, antes de os animais terem o pescoço retorcido, o que promoveria uma pantomima trágica antes do abate (HATOUM, 2008, p. 32).

Na mesa posta, a reconciliação. Doces e outras iguarias representariam não apenas a riqueza dos comerciantes imigrantes, mas a continuação de tradições culinárias. Assim somos convidados a sorver cheiros e sabores de folheados, esfihas, o pão com zatar, frutas secas e iguarias de frutas da região (HATOUM, 2008, p. 33-34). Em uma noite de Natal, a família recebe visitas e familiares. O evento da ceia natalina agrega música, dança e diversidade cultural. Hakim, o filho de Emilie, diz: "Antes da meia-noite, a vitrola tocava canções portuguesas e orientais ritmadas com palmas, e os vizinhos estrangeiros, vestidos a caráter, vinham cumprimentar Emilie e assistir as filhas de Mentaha dançarem após a ceia” (HATOUM, 2008, p. 34). A anfitriã ecoava na festa: “[...] os estrangeiros são sempre bem-vindos" (HATOUM, 2008, p. 37). Assim a vizinha portuguesa e a vizinha judia marroquina entre outros, estavam entre os convivas. Os Benemou do Marrocos sempre visitavam a casa de Emilie. Na festa, D. Sara Benemou é arguida sobre a inauguração da Sinagoga de Manaus ou se "em Rabat conheciam o tabule e a esfiha com picadinho de carneiro" (HATOUM, 2008, p. 36).

Os judeus de origem marroquina começaram a aportar em terras amazônicas desde o início do século XIX, com a abertura dos portos às nações amigas. O destino imigratório dos sírio-libaneses foi o mesmo dos marroquinos. Segundo Samuel Benchimol em $A$ formação social da Amazônia,

no último quartel do século XIX e no início do século XX, começou a chegar a Belém, Manaus e interior dos Estados do Pará, Amazonas e Acre um novo grupo de imigrantes, que haveria de ter participação destacada na economia e na sociedade amazônicas. Eram os sírio-libaneses, que deixaram as suas vilas, aldeias e cidades do Oriente Médio de Batroun, Baalbeck, Ghazir, Dimen, Ghosta, Jbeil e Beirute do Líbano, e de Ayo, Hamma e Damasco da Síria, para tentar a vida e "mourejar" na Amazônia, em Belém, Manaus, Porto Velho, Rio Branco, no beiradão e nos altos rios da seringa.

Essa corrente cultural também se realizou na forma de imigração familiar, com esposas e filhos, dado o caráter gregário e comunitário das suas formas tradicionais de vida. Quando vinham solteiros, pediam aos seus pais e parentes, que ficaram na Síria e no Líbano, que enviassem primas, parentes e moças conhecidas para contrair matrimônio, a semelhança do que faziam os judeus com os seus familiares marroquinos e outros grupos de imigrantes. E, assim, se mantinha a coesão da vida familiar, que muito ajudou na formação das 
casas de negócios e empresas desses imigrantes. (BENCHIMOL, 2009, p. 429).

Márcio Souza (2000, p. 105) afirma que "o látex fez toda uma civilização no norte do Brasil e os sefaradim foram um importante instrumento civilizatório". Além disso, continua Souza (2000, p. 106), assim como "os sírio e libaneses, os judeus não chegaram à Amazônia como colonos". Fugiram da pobreza, perseguições, violências e falta de trabalho. Na Amazônia viram, na extração e comércio da borracha, um caminho para o sustento, além da liberdade de culto encontrada. Em Relato de um certo Oriente e em Dois irmãos, conhecemos a história de duas famílias de origem libanesa. No primeiro romance, as famílias de origem árabe e judaica convivem amistosamente. O lar libanês tornou-se o local de encontro de estrangeiros. Nele, os judeus Benemou são retratados como bons vizinhos, frequentadores das festas da matriarca Emilie:

Essas reuniões continuaram na casa nova, mas foi na Parisiense que me deparei com sua existência. A conversa era exclusivamente em árabe, salvo os cumprimentos de algum transeunte conhecido, ou a visita de um ou outro vizinho, alguns deles estrangeiros, como a família do poveiro Américo, os Benemou do Marrocos, e Gustav Dorner, o rapaz de Hamburgo; todos amicíssimos de Emilie”. (HATOUM, 2008, p. 52).

Em Dois irmãos, conhece-se a história de uma família sírio-libanesa na Amazônia, tendo, como núcleo dramático, a inimizade entre dois irmãos. A aproximação ao motivo bíblico é clara. Como Esaú e Jacó, os irmãos Yaqub e Omar se odeiam. A propósito deste assunto, há a dissertação "Dois Irmãos e seus precursores: um diálogo entre o romance de Milton Hatoum, a Bíblia e a mitologia ameríndia” de Lucius Flávio de Mello (2013). Este atesta que

basta começar a ler o romance hatouniano para perceber que, logo nas primeiras páginas, a obra intencionalmente evoca a narrativa bíblica dos embates familiares, dos irmãos em conflito. Contudo, a dificuldade maior é afirmar quem é quem nesse romance Omar e Yaqub/Esaú e Jacó mostram-se dois pares de gêmeos separados por narrativas distintas e, ao mesmo tempo, duplas tão geminadas ora por estranhamentos ora por semelhanças. (MELLO, 2013, p. 10). 
Lucius de Mello cita ainda a presença judaica nos três romances de Milton Hatoum abordados neste artigo, mas não desenvolve a temática. Ele afirma que fez apenas "breves registros" (MELLO, 2013, p. 14) com o intuito de destacar as conexões entre a narrativa bíblica e a narrativa do autor manauara.

O que a tradição judaico-cristã fala sobre Esaú e Jacó? Tanto na Bíblia, como no Midrash, Deus mostra preferência por Jacó. No texto neotestamentário, Deus rejeita a Esaú e ama a Jacó, como se vê em Romanos 9: 13. No Midrash, sobre Jacó, Hashem afirma formar uma nação e uma comunidade de nações, que o texto midráshico diz tratarse da tribo de Benjamim e das demais tribos de seus irmãos (WEISSMAN, 2006, p. 286). Jacó era um bom filho e dedicado à tradição de seus antepassados. Quanto a Esaú, Hashem o desprezou por seus vários consórcios com mulheres cananeias que fizeram com que seus pais padecessem de tristezas e decepções. (WEISSMAN, 2006, p. 220). Uma profecia dita a Rebeca, antes do nascimento dos gêmeos, antecipa uma vida de guerras e rancores entre os irmãos: "Há duas nações em teu seio, dois povos saídos de ti, se separarão, um povo dominará um povo, o mais velho servirá ao mais novo" (GÊNESIS, 25: 23). Aproximando as narrativas bíblica e a hatouniana, assim como Rebeca, a matriarca Zana tem preferência por um filho. E mesmo aí é necessário considerar uma inversão das preferências, já que Zana elegeu o irmão pródigo e bon vivant, bem ao modo dionisíaco e Halim o filho estudioso e trabalhador, cultor de um equilíbrio apolíneo. No relato bíblico, Rebeca protege o filho sensato e o pai o devasso, porque era primogênito. É neste cenário de lutas e mágoas que a matriarca árabe, na ânsia de bem viver a Amazônia, festeja com muitos estrangeiros, ainda que se depare com perdas e solidão.

A digressão sobre a similaridade entre o texto bíblico e a narrativa de Hatoum conduz-nos a pensar em um contraponto. Embora os gêmeos Omar e Yaqub jamais tenham desfeito a inimizade, judeus e árabes cristãos ou muçulmanos, conviveram pacificamente em Dois irmãos. Neste romance, os bailes de carnaval eram realizados no casarão de Sultana Benemou, amiga judia da família de Zana e Halim. Todos desejavam ir para as festas dos Benemou. Lá foi o lugar onde os irmãos cobiçaram a bela Lívia e manifestaram o ódio que sempre foi latente. Repete-se em Dois irmãos, a referência à família Benemou que se vê em Relatos de um certo Oriente. Além disso, o narrador fala sobre as polacas que eram visitadas por Halim na juventude (HATOUM, 2006, p. 164).

A Amazônia, assim como o Rio de Janeiro, São Paulo e o Rio Grande do Sul, por exemplo, recebeu judias polacas que foram prostituídas pela máfia judaica Zwi Migdal. O gaúcho Moacyr Scliar em $O$ ciclo das águas, a baiana-carioca Esther Largman em 
Jovens polacas e o amazonense Marcos Serruya em Cabelos de fogo construíram romances que falam sobre judias prostituídas. Quanto a isso, pensamos que a citação presente em Dois irmãos poderia dizer respeito não unicamente às judias alcunhadas de polacas em um nicho de prostituição, mas às prostitutas que atendessem a um certo tipo étnico caucasiano. O fato é que polaca virou um epíteto para prostituta. Segundo Berta Waldman (2012, p. 42),

mesmo que o número de moças traficadas tenha sido proporcionalmente pequeno, e, no Brasil, tudo indica que as brasileiras superavam o número de prostitutas estrangeiras, o fenômeno teve repercussões amplas, a ponto de se associar o termo "polaca" a "prostituta", principalmente no Rio de Janeiro e em São Paulo.

De todo modo, dada a presença de judias prostituídas em Manaus, como revela Samuel Benchimol (2008, p. 75), tema presente em Cabelos de fogo de Marcos Serruya, a citação também poderia evocar às moças judias que foram prostituídas pela Zwi Migdal.

Em outro romance de Milton Hatoun, Órfãos do Eldorado, há uma família de judeus que logra maior destaque em relação aos Benemou presentes nas histórias dos sírio-libaneses. Já não se trata de simples menções diretas, como se vê em Relato de um certo Oriente ou mesmo de citações indiretas como se percebe em Dois irmãos. Os Becassis, uma família de Belém, têm maior representatividade neste romance que conta a história de Arminto e sua paixão por Dinaura, a órfã do convento das Carmelitas. Inebriado pelo sonho de estar com Dinaura, Arminto dilapida o patrimônio de se pai Amando. Na busca por vender as últimas posses, trava contato com a família Becassis, judeus marroquinos sefarditas, e planeja casar-se com a bela viúva Estrela para não perder o “palácio branco" (HATOUM, 2008, p. 89). Cego de mágoas e de rancor do pai, Arminto vê no filho de Estrela, uma cópia paterna e imagina que o rapazola, que olha enviesado para ele, é seu irmão. Fantasias, diz o amigo Estiliano. O casamento jamais acontece. Os Becassis vão embora e Arminto continua a divagar por Dinaura.

A presença judaica na Amazônia é sublimada, em Órfãos do Eldorado, em Estrela, a judia encantadora que é apenas vista, pensada e desejada durante todo o romance. Dela, Arminto busca sorver sensualidade, apesar do recato que ela conserva. O velho Becassis, com "barba de patriarca" (HATOUM, 2008, p. 71), recebe uma descrição telúrica, real, áspera: 
Becassis estava sentado entre Estrela e Azário, um rapaz esquisito. Ela era altiva, o cabelo comprido e cacheado roçava a borda da mesa. Observei o corpo empinado, as mãos delicadas, o rosto bem talhado, que escondia alguma coisa no fundo dos olhos cinzentos. Como admirei os olhos da forasteira. Era a segunda vez que via a mulher, a primeira havia sido só de longe. Ela vivia como uma cativa, não queria mostrar a beleza. O velho notou que eu estava hipnotizado por Estrela. Eu ainda não sabia que era filha dele, os judeus marroquinos e os árabes tinham fama de mulherengos, e os mais velhos costumavam casar com mocinhas. O ciúme nos olhos dele não era cisma de esposo, era de pai. (HATOUM, 2008, p. 72).

Neste romance, além dos Becassis, há o judeu Salomito Benchaya, dono de uma pensão que hospeda a família de Estrela. Mas este também apenas revela o nicho étnico que encontramos nos textos de Hatoum. Benchaya e Becassis são judeus na Amazônia, assim como os sírio-libaneses representam o seu grupo étnico nos dois romances de Hatoum. Para a professora Regina Igel (2012, p. 1), ao comparar a produção literária de Milton Hatoum e Moacyr Scliar,

estes dois escritores brasileiros - Moacyr Scliar (1937-2011) e Milton Hatoum (1952-) são vistos por estudiosos, em geral, como "escritores étnicos", pois cada um deles fez, de seu legado étnico-cultural, o fulcro de suas obras literárias. Scliar desvendou os judeus no Brasil, começando pela comunidade judaica no sul do país, enquanto Hatoum destaca a comunidade de imigrantes de origem libanesa no Norte. Dos polos norte e sul, dois romancistas que, entre tantos brasileiros dedicados à arte de escrever bem, revelam seus talentos como narradores ao mergulharem na atmosfera física, cultural, psicológica e moral em que cresceram. Esses são alguns dos pontos coincidentes expressados por eles em relação ao meio ambiente que transpuseram à vida literária. $\mathrm{E}$, ao mesmo tempo, há vários outros elementos que, ao contrário, expõem uma perceptível distinção entre os dois, seja pelo encaixe de suas experiências no labor literário, pela atmosfera que distribuem entre as narrativas, ou seja pela diferença de intensidade da cor local que impregna suas narrativas.

Embora Hatoum abrace o "legado étnico-cultural" sírio-libanês, de que fala a professora Igel, ele não fechou os olhos para outros grupos étnicos. Os judeus, nos romances acima comentados, os japoneses em Cinzas do Norte (2005), representados pela família Oyama, os portugueses, ingleses e alemães que abundam nos seus romances e contos mostram um certo cosmopolitismo a viver a Amazônia. Às vezes, não se trata do imigrante, mas do estrangeiro em trânsito, em busca dos lucros comerciais, das 
oportunidades que a terra amazônica permite. Alguns a sugam, outros casam-se, constituem família, plantam seringas, fazem o comércio e trocam culturas, ecoando, com alegria, a voz do noivo e da noiva, em alusão ao texto bíblico (JEREMIAS 33: 11).

\section{Considerações finais}

Os romances de Hatoum inserem a multiplicidade cultural e étnica no contexto narrativo deles, como o fez também um outro escritor amazônida, filho de judeu marroquino: Paulo Jacob. No seu romance Vila Rica das Queimadas (1976), de Jacob, conhece-se a história do regatão Jamil, imigrante sírio-libanês, desbravador dos rios e florestas amazônicos e amante das caboclas da região. Na mesma pegada étnica, Jacob, em 1990, publica Um pedaço de lua caía na mata, romance que apresenta as vivências do judeu Salomão Farah nos rincões amazônicos e a sua luta para preservar a fé judaica na sua família.

Contígua à diversidade cultural dos estrangeiros, há a cultura nativa sedutora, cálida, envolvente, como uma Dinaura no caminho de Arminto. Ela chama, alicia para viver uma Amazônia autóctone visível e invisível, de mata fechada e de rios caudalosos e enigmáticos, que seduz estrangeiros, como Ismael e Isaque, e os leva a viver em paz.

Northrop Frye em $O$ código dos códigos atribui a Ismael uma condição de filho rejeitado, conforme a tradição bíblica. Ele acrescenta que Ismael carrega uma carga dramática aumentada não apenas pela errância obrigatória, instituída pelo pai, mas pela quase morte no deserto. Segundo ele,

a Bíblia não aceita a concepção grega de herói, a figura humana "maior
do que o comum" em relação a porte, poderes, linhagem e articulação,
que tão seguido parece ter um destino divino quase ao seu alcance. Mas
as marcas da tragédia, para um leitor que as aprecie, estão presentes em
alguns desses personagens desprezados: na errância de Caim, diante da
recusa de seu sacrifício sem sangue (até ali); na quase morte por fome
de Ismael, com sua mãe, no deserto, e no lamento de seu pai: "Seja do
teu agrado que Ismael viva em tua presença!'’(Gênesis, 17:18); no
grito amargo de Esaú, quando descobre com quanta insensibilidade foi
traído: "Dá-me também a mim a tua bênção, meu pai"(Gênesis, 27:34).
(FRYE, 2004, p. 270). GRIFOS NOSSOS.

Considerando a presença judaica nos romances de Milton Hatoum, não há rejeitados nem excluídos, há apenas irmãos milenarmente aparentados que, na Amazônia, 
padeceram de dores e trabalhos semelhantes e ousaram as mesmas conquistas, atenuando o drama da errância de Ismael e de Isaque (por contiguidade Jacó, Israel) e da inimizade que os desune por séculos, como se o lamento de Abraão ao Eterno fora ouvido: Abraão disse a Deus: "Oh! Que Ismael viva diante de ti!" (GÊNESIS 17: 18). Na Amazônia, em paz estão.

\section{Referências}

BENCHIMOL, Samuel. Amazônia: Formação social e cultural. Manaus: Editora. Valer, 2009.

BENCHIMOL, Samuel. Eretz Amazônia. Os judeus na Amazônia. Manaus: Valer, 2008. BEREZIN, Rifca. Projeções da Bíblia na literatura hebraica: O "Midrash" moderno. In: LEWIN, H. (org.) Judaísmo - memória e Identidade. Rio de Janeiro: Programa de Estudos Judaicos/Departamento de Ciências Sociais/UERJ, Volume I, 1997. p. 187-200. BÍBLIA DE JERUSALÉM. São Paulo: Paulus, 1985.

FRYE, Northop. O código dos códigos. Trad. Flávio Aguiar. São Paulo: Boitempo, 2004. HADI, Mahdi Abdul, A History of Jerusalem. Jerusalem Reader: from occupation to city of peace, edited by Ali Kazak, Canberra: Palestine Publications, (1st edition 1997, 2nd edition 2003), 3rd edition, 2019, p. 12-24.

HATOUM, Milton. Dois irmãos. São Paulo: Companhia das Letras, 2006.

HATOUM, Milton. Órfãos do Eldorado. São Paulo: Companhia das Letras, 2008. (Coleção Mitos).

HATOUM, Milton. Relato de um certo Oriente. São Paulo: Companhia das Letras, 2008. IGEL, Regina. Moacyr Scliar e Milton Hatoum: semelhanças e diferenças. Arquivo Maaravi. Revista Digital de Estudos Judaicos da UFMG. Belo Horizonte, v. 6, n. 11, 2012. Disponível em: <http://www.periodicos.letras.ufmg.br/index.php/maaravi/ article/view/3078/3032>. Acesso em: 18 jun. 2021.

LAREDO, Isaac. Memórias de un viejo tangerino. Madrid: C. Bermejo Impresor, 1935. MACEDO, José Rivair. Os filhos de Cam: a África e o saber enciclopédico medieval. SIGNUM: Revista da ABREM, Vol. 3, p. 101-132, 2001.

MELLO, Lucius Flávio. Dois Irmãos e seus precursores: um diálogo entre o romance de Milton Hatoum, a Bíblia e a mitologia ameríndia. 2013. f 140. Dissertação. Faculdade de Filosofia, Letras e Ciências Humanas, Universidade de São Paulo, 2013. 
SALGADO, Elias. O fim do mundo e outras histórias de beira-rio. Rio de Janeiro: Talú Cultural, 2015.

SAN AGOSTÍN. Obras completas de San Agustín. Escritos vários. Introducciones, versión, notas e índices de Teodoro C. Madrid. Madrid: Biblioteca de escritores cristianos, 1995.

SCLIAR, Moacyr; SOUZA, Márcio. Entre Moisés e Macunaíma. Os Judeus que descobriram o Brasil. Rio de Janeiro: Garamond, 2000.

VARAZZE, Jacopo de. Legenda áurea: vidas de santos. Tradução de Hilário Franco Jr. São Paulo: Companhia das letras, 2003.

WALDMAN, B. Entre braços e pernas: Prostitutas estrangeiras na literatura brasileira do século XX. Remate de Males, Campinas, SP, v. 22, n. 2, p. 25-53, 2012. Disponível em: $<$ https://periodicos.sbu.unicamp.br/ojs/index.php/remate/article/view/8636158>. Acesso em: 18 jun. 2021.

WEISSMAN. Moshe. El Midrash dice. Buenos Aires: Editorial Bnei Sholem, 2006. 